\title{
$E$ The clinical and economic costs of treating cervical radiculopathy: the age-old question of the anterior versus posterior approach
}

\author{
Anthony C. Lau, MD, and Michael Y. Wang, MD \\ Department of Neurological Surgery, University of Miami Miller School of Medicine, Miami, Florida
}

$\mathrm{I}$ $\mathrm{N}$ this article, Nguyen et al. ${ }^{8}$ explore the differences between anterior cervical discectomy and fusion (ACDF) and posterior cervical foraminotomy (PCF) with respect to the postoperative neural foramen size in a cadaveric model. They report that PCF results in a significantly larger neural foramen compared with the untreated control group. This larger foramen size persisted in flexion and extension of the cervical spine when compared with controls. In ACDF-treated specimens, the foramen size did not change significantly compared with untreated controls, even with resection of the posterior one-third of the uncovertebral joint. Foramen size was significantly decreased in the extension position with ACDF and uncoverterbral joint resection, supporting the notion that anterior cervical discectomies without upfront fusions are inherently unstable. Although these findings seem to favor the PCF as the superior technique biomechanically, the authors in their discussion correctly acknowledge the fact that the clinical outcomes of the ACDF and PCF appear to be equivalent. They further postulate that the postsurgical resolution of pain is possibly less related to the postoperative foramen size, than to the alleviation of compression of vascular structures that were causing radicular artery ischemia or venous congestion.

Since its inception in the 1950s, the ACDF approach has undergone various modifications, primarily in grafting and plating systems. At its core, the anterior approach has a number of advantages that have made it increasingly popular over the years. The ACDF allows bilateral access to nerve roots from a single approach; requires minimal muscle dissection, resulting in less patient discomfort; allows access to more centrally located discs; and other advantages. In addition, the ACDF approach allows for indirect neural decompression through restoration of in- terbody height. The need for fusion after an anterior discectomy is generally accepted-clinical studies have shown increased rates of kyphotic deformities without fusion. ${ }^{13}$ Consequently, a loss of motion segments leads to increased rates of adjacent-segment degeneration and pseudarthrosis.

Similarly, the PCF approach has gone through a number of modifications since its development in the 1950s, resulting in full endoscopic, tubular retraction, and open microscopic methods to accomplish a PCF. The major advantages of the PCF are that it does not traverse any critical structures during the approach, and that it preserves motion segment mobility. The disadvantages associated with the posterior approach are that it may destabilize the spine, the muscle dissection needed can cause persistent neck and shoulder pain, and the technique is limited to isolated nerve root entrapment. Cadaveric studies have shown that leaving approximately $50 \%$ of the facet will not destabilize the spine. ${ }^{14}$ However, despite the fact that there is no gross instability, long-term studies have shown same-segment disease rates after PCF of $3.2 \%$ at 5 years and $5.0 \%$ at 10 years, with adjacent-segment disease rates of $6.7 \%$ at 10 years. $^{3}$

Studies directly comparing the ACDF and PCF approaches reported no significant difference in clinical outcomes, with clinical improvement rates ranging from $88 \%$ to $100 \%$ for the ACDF and from $89 \%$ to $100 \%$ for the PCF., ${ }^{4,5,10,12}$ Reoperation rates of between $2 \%$ and $24 \%$ were reported for the ACDF approach and between $4 \%$ and $27 \%$ for the PCF approach, again with no statistically significant difference between the 2 groups. ${ }^{5,10,12}$ To further elucidate the true reoperation rates between the 2 techniques, Lubelski et al. ${ }^{6}$ adopted a propensitymatched model to compare ACDF and PCF reoperation rates. They found a statistically nonsignificant reoperation 
rate of $4.1 \%$ for ACDF and $6.1 \%$ for PCF within 2 years at the same index level.

Some of the strongest evidence comparing the 2 techniques comes from a study by Ruetten et al. ${ }^{9}$ In this prospective, randomized, controlled study comparing an endoscopic PCF with the conventional ACDF performed with a single-level polyetheretherketone cage without plating, 175 patients were randomized to either PCF or ACDF. Subjective satisfaction was achieved in $96 \%$ of the PCF group and $91 \%$ of the ACDF group. Complete abolishment of pain was achieved in $88 \%$ of ACDF and $89 \%$ of PCF cases, as indicated by visual analog scale pain scores of the arm and neck. Revision rates were reported as $4.7 \%$ and $6.7 \%$ for ACDF and PCF, respectively. No difference in complication rates was seen between the 2 procedures. Taken together, the available evidence suggests that these 2 techniques are at least equivalent in clinical efficacy, reoperation rates, and patient satisfaction. Whereas the complication rates appear to be similar with both techniques, the complication profile differs greatly between the 2 procedures.

Given that there is no clearly clinically superior technique, recent investigations have been directed at the relative economic value of each procedure. Tumialan et al. ${ }^{11}$ calculated the direct and indirect costs of the ACDF compared with the PCF in a military setting, and reported direct costs of $\$ 10,078$ for ACDF compared with $\$ 3570$ for $\mathrm{PCF}$, for a difference of $\$ 6508$ per procedure performed. The indirect costs were estimated at $\$ 13,586-\$ 24,045$ more per individual for the ACDF group, with the average return to work time in the PCF group being 4.8 weeks and in the ACDF group being 19.6 weeks. Mansfield et al. ${ }^{7}$ conducted a similar investigation in a civilian population, reporting a length of stay for the ACDF group of 1.41 days, compared with the PCF, which was 0.57 days. The average cost for PCF was $\$ 4320$ per case, with operating room supplies costing $\$ 1304$. The direct costs were $\$ 8192$ per case for the ACDF group, with average instrumentation costs at $\$ 4447$. Finally, Alvin et al. ${ }^{1}$ looked specifically at the 1-year cost/utility ratio of 45 patients treated with ACDF compared with 25 patients treated with PCF. These authors reported that the 1-year cost/utility ratio for the PCF cohort was significantly lower ( $\$ 79,856 /$ qualityadjusted life year [QALY] gained) than that for the ACDF cohort (\$131,951/QALY gained).

Overall, the complication profiles of the PCF and ACDF procedures vary greatly and are related primarily to the approach and need for fusion, although rates remain similar. The desire for better patient outcomes continues to drive new innovations in technology with both techniques-with minimally invasive techniques minimizing tissue trauma in the PCF approach and arthroplasty techniques reducing the need for fusions in the ACDF approach. But because new technology often comes with increasing health care costs, the economics of each procedure will come under increasing scrutiny. Thus, we eagerly await the results of the upcoming Foraminotomy ACDF Cost-Effectiveness Trial (FACET) in the Netherlands, ${ }^{2}$ which will serve to further our understanding of the clinical and economic ramifications of cervical radiculopathies and their management.

https://thejns.org/doi/abs/10.3171/2017.3.SPINE17152

\section{References}

1. Alvin MD, Lubelski D, Abdullah KG, Whitmore RG, Benzel EC, Mroz TE: Cost utility analysis of anterior cervical discectomy and fusion with plating (ACDFP) versus posterior cervical foraminotomy (PCF) for patients with single-level cervical radiculopathy at 1-year follow-up. Clin Spine Surg 29:E67-E72, 2016

2. Broekema AEH, Kuijlen JMA, Lesman-Leegte GAT, Bartels RHMA, van Asselt ADI, Vroomen PCAJ, et al: Study protocol for a randomised controlled multicentre study: the Foraminotomy ACDF Cost-Effectiveness Trial (FACET) in patients with cervical radiculopathy. BMJ Open 7:e012829, 2017

3. Clarke MJ, Ecker RD, Krauss WE, McClelland RL, Dekutoski MB: Same-segment and adjacent-segment disease following posterior cervical foraminotomy. J Neurosurg Spine 6:5-9, 2007

4. Herkowitz HN, Kurz LT, Overholt DP: Surgical management of cervical soft disc herniation. A comparison between the anterior and posterior approach. Spine (Phila Pa 1976) 15:1026-1030, 1990

5. Korinth MC, Kruger A, Oertel MF, Gilsbach JM: Posterior foraminotomy or anterior discectomy with polymethyl methacrylate interbody stabilization for cervical soft disc disease: results in 292 patients with monoradiculopathy. Spine (Phila Pa 1976) 31:1207-1214, 2006

6. Lubelski D, Healy AT, Silverstein MP, Abdullah KG, Thompson NR, Riew KD, et al: Reoperation rates after anterior cervical discectomy and fusion versus posterior cervical foraminotomy: a propensity-matched analysis. Spine J 15: 1277-1283, 2015

7. Mansfield HE, Canar WJ, Gerard CS, O'Toole JE: Singlelevel anterior cervical discectomy and fusion versus minimally invasive posterior cervical foraminotomy for patients with cervical radiculopathy: a cost analysis. Neurosurg Focus 37(5):E9, 2014

8. Nguyen J, Chu B, Kuo CC, Leasure JM, Ames C, Kondrashov D: Changes in foraminal area with anterior decompression versus keyhole foraminotomy in the cervical spine: a biomechanical investigation. J Neurosurg Spine [epub ahead of print October 13, 2017. DOI: 10.3171/2017.2.SPINE141237]

9. Ruetten S, Komp M, Merk H, Godolias G: Full-endoscopic cervical posterior foraminotomy for the operation of lateral disc herniations using 5.9-mm endoscopes: a prospective, randomized, controlled study. Spine (Phila Pa 1976) 33: $940-948,2008$

10. Selvanathan SK, Beagrie C, Thomson S, Corns R, Deniz K, Derham C, et al: Anterior cervical discectomy and fusion versus posterior cervical foraminotomy in the treatment of brachialgia: the Leeds spinal unit experience (2008-2013). Acta Neurochir (Wien) 157:1595-1600, 2015

11. Tumialan LM, Ponton RP, Gluf WM: Management of unilateral cervical radiculopathy in the military: the cost effectiveness of posterior cervical foraminotomy compared with anterior cervical discectomy and fusion. Neurosurg Focus 28(5):E17, 2010

12. Wirth FP, Dowd GC, Sanders HF, Wirth C: Cervical discectomy. A prospective analysis of three operative techniques. Surg Neurol 53:340-346, 2000

13. Xie JC, Hurlbert RJ: Discectomy versus discectomy with fusion versus discectomy with fusion and instrumentation: a prospective randomized study. Neurosurgery 61:107-116, 2007

14. Zdeblick TA, Zou D, Warden KE, McCabe R, Kunz D, Vanderby R: Cervical stability after foraminotomy. A biomechanical in vitro analysis. J Bone Joint Surg Am 74:22-27, 1992

\section{Disclosures}

The authors report no conflict of interest. 


\section{Response}

Jacqueline Nguyen, MD, ${ }^{1}$ Bryant Chu, MS,${ }^{2}$ Calvin C. Kuo, MD, ${ }^{3}$ Jeremi Leasure, MS, ${ }^{2}$ Christopher Ames, MD, ${ }^{4}$ and Dimitriy Kondrashov, MD

${ }^{1}$ San Francisco Orthopaedic Residency Program; ${ }^{2}$ The Taylor Collaboration, San Francisco; ${ }^{3}$ Kaiser Permanente Medical Center, Oakland; ${ }^{4}$ Department of Neurosurgery, University of California, San Francisco Medical Center; and ${ }^{5}$ Department of Orthopaedic Surgery, St. Mary's Spine Center, San Francisco, California

We have read with great interest the editorial by Drs. Anthony Lau and Michael Wang summarizing our cadaveric study examining the differences between ACDF and PCF with respect to foraminal size. We appreciated the succinct summary of our study, as well as the in-depth review of the history of both procedures. As is often true, one's understanding of the history and evolution of particular surgical techniques results in a more detailed understanding of the procedure, as well as individual steps and unique challenges required to accomplish the surgical tasks at hand. Drs. Lau and Wang have provided an overview of the clinical results of both procedures, which supplements the review in our paper, however, focusing in great detail on minimally invasive as well as less-invasive techniques pertaining to PCF.

Additionally, Drs. Lau and Wang have provided an excellent overview of both the direct and indirect costs associated with the procedures, and have touched upon the cost-effectiveness of both procedures. We wholeheartedly agree with Drs. Lau and Wang that both ACDF and PCF are currently the "co-gold" standards for the treatment of single-level cervical nerve root compression. Spinal arthroplasty surgery experts might add that there is enough clinical evidence to create a "triple" gold standard for the treatment of single-level cervical radiculopathy, which would include PCF, ACDF, and cervical arthroplasty.
We would like to highlight that our study has focused selectively on the foraminal dimensions, and would most likely be applicable in cases where the cervical exiting nerve root is compressed by uncovertebral hypertrophy (bony stenosis of the foramen). Soft cervical disc herniations would certainly require a slightly different approach, both anteriorly and posteriorly. Anteriorly, one would most likely need to remove the posterior longitudinal ligament to reach the herniation, and also might not need to remove the uncovertebral osteophyte complex. Moreover, some cervical soft disc herniations-for instance, central herniations-are simply inaccessible from the back, and in those cases the only option is to approach the pathology anteriorly. Thus, one may view the ACDF as the more universal tool, although it is the one that seems to have a moderately higher cost.

The main purpose of our study was to validate and objectify prior experiences with PCF and to further substantiate that it is still a very viable treatment option for select patients. We offer patients PCF in cases of 1- or 2-level unilateral nerve root compression, if the pathology is lateral to the spinal cord with no significant complaints of axial neck pain. We also use it quite often as a salvage procedure after a patient who has undergone ACDF still reports radiculopathy within the fused segment.

Naturally, the issue of adjacent-segment disease is as controversial as ever. Drs. Lau and Wang quote comparable numbers of patients with adjacent-segment disease between ACDF and PCF. One way of viewing that study would be from the point of relentless natural progression of degenerative disc disease, and with minimal contribution from the surgery itself. Certainly our study did not even attempt to address issues of either clinical efficacy or of adjacent-segment breakdown.

Overall, we thought that the editorial by Drs. Lau and Wang gave a very updated and comprehensive overview of the pros and cons of both surgical techniques. 